\title{
New chemistry of diazafulvenium methides: one way to pyrazoles
}

\author{
Teresa M. V. D. Pinho e Melo, ${ }^{*}$ Maria I. L. Soares and António M. d'A. Rocha Gonsalves \\ Departamento de Química, Universidade de Coimbra, 3004-535 Coimbra, Portugal
}

Received 23 September 2005; revised 15 November 2005; accepted 18 November 2005

Available online 5 December 2005

\begin{abstract}
Diazafulvenium methides generated from the solution pyrolysis of pyrazolo[1,5-c][1,3]thiazole-2,2-dioxides participate in $[8 \pi+2 \pi]$ cycloadditions giving pyrazolo $[1,5-a]$ pyridine derivatives. 1-Methyl-diazafulvenium, generated under flash vacuum pyrolysis reaction conditions, undergoes an intramolecular sigmatropic $[1,8] \mathrm{H}$ shift giving 1-vinyl-1 $H$-pyrazoles.

(C) 2005 Elsevier Ltd. All rights reserved.
\end{abstract}

The study of pericyclic reactions of extended dipoles (with more than $4 \pi$ electrons) is an almost unexplored research area. However, Storr and co-workers explored the reactivity of pyrrolo[1,2-c]thiazole-2,2-dioxides (1) and pyrazolo[1,5-c][1,3]thiazole-2,2-dioxides (3) and proved that they can be considered masked aza- and diazafulvenium methides ( $\mathbf{2}$ and $\mathbf{4}) .{ }^{1}$ Earlier, Padwa and coworkers described unsuccessful attempts to extrude $\mathrm{SO}_{2}$ from pyrrolo[1,2-c]thiazole-2,2-dioxides for the generation of an azafulvenium methide, both thermally $\left(300{ }^{\circ} \mathrm{C}\right)$ and photochemically. ${ }^{2}$ Azafulvenium methides can be considered as 'higher-order' azomethine ylides and, in principle, can act as $4 \pi$ 1,3-dipoles or as $8 \pi$ 1,7-dipoles.
Storr and co-workers found that the generation of 1azafulvenium methides (2a-d) by the thermal extrusion of sulfur dioxide from pyrrolo[1,2-c]thiazole-2,2-dioxides 1 could be achieved under flash vacuum pyrolysis (FVP) reaction conditions. They described the first evidence for trapping of transient 1-azafulvenium methide systems in pericyclic reactions. These extended dipolar systems $\mathbf{2 a}-\mathbf{c}$ undergo sigmatropic $[1,8] \mathrm{H}$ shifts giving vinylpyrroles and the acyl derivatives $2 \mathbf{d}$ electrocyclise to give pyrrolo[1,2-c] $[1,3]$ oxazines. ${ }^{1}$

It was also reported that the $\mathrm{SO}_{2}$ extrusion of the pyrazole derivative $3^{3}$ occurs more easily than from the analogous pyrrolo sulfone. The authors reported that the<smiles>[R]C1C(=C(C)OC)C(C(C)=O)=C2N1C([R])([R])C2([R])[2H]</smiles><smiles>[R]C([R])=C1C(C(=O)OC)=C(C(C)=O)C(C)=[N+]1[CH]C</smiles>

2a $\mathrm{R}^{1}=\mathrm{R}^{2}=\mathrm{H} ; \mathrm{R}^{3}=\mathrm{CH}_{3}$ 2b $\mathrm{R}^{1}=\mathrm{H} ; \mathrm{R}^{2}=\mathrm{CH}_{3} ; \mathrm{R}^{3}=\mathrm{H}$ 2c $\mathrm{R}^{1}=\mathrm{R}^{2}=\mathrm{CH}_{3} ; \mathrm{R}^{3}=\mathrm{H}$ 2d $R^{1}=H ; R^{2}=$ COR; $R^{3}=H$<smiles>C=C=Cc1nn2c(c1C(C)=O)CS(=O)(=O)C2</smiles>

3<smiles></smiles>

4<smiles></smiles>

2e $\mathrm{R}^{1}=\mathrm{Ph} ; \mathrm{R}^{2}=\mathrm{CH}_{3}$ 2f $\mathrm{R}^{1}=\mathrm{CH}_{2} \mathrm{Ph} ; \mathrm{R}^{2}=\mathrm{CH}_{3}$ 2g R $\mathrm{R}^{1}=\mathrm{CH}_{2} \mathrm{CH}_{3} ; \mathrm{R}^{2}=\mathrm{CH}_{3}$ 2h $\mathrm{R}^{1}=\mathrm{CH}\left(\mathrm{CH}_{3}\right)_{2} ; \mathrm{R}^{2}=\mathrm{CH}_{3}$ 2i $\mathrm{R}^{1}=\mathrm{C}\left(\mathrm{CH}_{3}\right)_{3} ; \mathrm{R}^{2}=\mathrm{CH}_{3}$ 2k $\mathrm{R}^{1}=\mathrm{CH}_{3} ; \mathrm{R}^{2}=\mathrm{Ph}$ 2l $\mathrm{R}^{1}=\mathrm{R}^{2}=\mathrm{Ph}$ $2 \mathrm{~m} \mathrm{R} \mathrm{R}^{1}=\mathrm{CH}_{3} ; \mathrm{R}^{2}=\mathrm{H}$ 2n $R^{1}=P h ; R^{2}=H$

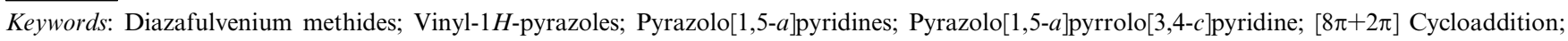
Sigmatropic shift.

* Corresponding author. Tel.: +351239 854475; fax: +351239826068; e-mail: tmelo@ci.uc.pt
} 
1,2-diazafulvenium methide 4 did not react with $N$ phenylmaleimide or dimethyl acetylenedicarboxylate but could be intercepted in $8 \pi+2 \pi$ cycloaddition with silylated acetylenes giving adducts resulting from the addition across the 1,7-position. ${ }^{1}$

We have further studied the reactivity of azafulvenium methides including the reactivity of a range of new derivatives $\mathbf{2 e}-\mathbf{n}$ and showed that these transient $8 \pi$ 1,7-dipole systems are interesting intermediates for the synthesis of functionalised heterocyclic compounds. The intramolecular trapping of the 1,7-dipoles in pericyclic reactions, namely sigmatropic $[1,8] \mathrm{H}$ shifts and $1,7-$ electrocyclisations, allowed the synthesis of $N$-vinyl- and $C$-vinylpyrroles, which, under flash vacuum pyrolysis conditions, are converted into heterocycles where another ring system is annulated to pyrrole. ${ }^{4}$

1,2-Diazafulvenium methides' chemistry has also attracted our attention and our preliminary results are described in this letter. We prepared the $4 H$-pyrazolo$[1,5-c][1,3]$ thiazole-5,5-dioxide $\mathbf{3}^{1,3}$ and observed that it undergoes $\mathrm{SO}_{2}$ extrusion in the solution to give 1,2-diazafulvenium methide 4, which could be trapped by reacting with bis(trimethylsilyl)acetylene, confirming the result reported by Storr and co-workers. ${ }^{1}$ In our hands, dimethyl 5,6-bis(trimethylsilyl)-4,7-dihydro- pyrazolo[1,5-a]pyridine-2,3-dicarboxylate 6 was obtained in $54 \%$ yield together with the formation of the aromatised derivative 7 in $7 \%$ yield. However, the dipolar system 4 also participates in the cycloaddition with $\mathrm{N}$ phenylmaleimide giving the corresponding cycloadduct $\mathbf{5}^{5}$ in $87 \%$ yield (Scheme 1). This result contradicts the reported experimental observation although the reactivity of this 1,7 -dipole 4 towards $[8 \pi+2 \pi]$ cycloaddition, characterised by the participation in the reaction with both electron-rich and electron-deficient dipolarophiles, is in agreement with the reported MO calculations for the unsubstituted diazafulvenium methide. ${ }^{1}$

We decided to explore the possibility of generating new diazafulvenium methides systems and study their reactivity in the absence of dipolarophiles. 3-Methyl-pyrazolo[1,5-c][1,3]thiazole-2,2-dioxide $\mathbf{1 2}$ was prepared as outlined in Scheme 2. Sydnone $\mathbf{1 0}$ is a stable mesoionic species, which can be isolated and undergoes 1,3-dipolar cycloaddition with DMAD to give pyrazolo[1,5-c]$[1,3]$ thiazole 11. The oxidation of $\mathbf{1 1}$ with MCPBA gives sulfone 12 (Scheme 2).

Carrying out flash vacuum pyrolysis of sulfone $\mathbf{1 2}$ at $500{ }^{\circ} \mathrm{C}$, we obtained 1-vinyl-1 $\mathrm{H}$-pyrazole $\mathbf{1 4}^{6}$ selectively. When the FVP was carried out at $700{ }^{\circ} \mathrm{C}$ the same 5methyl-1-vinyl-1 $H$-pyrazole $\mathbf{1 4}$ was obtained, together

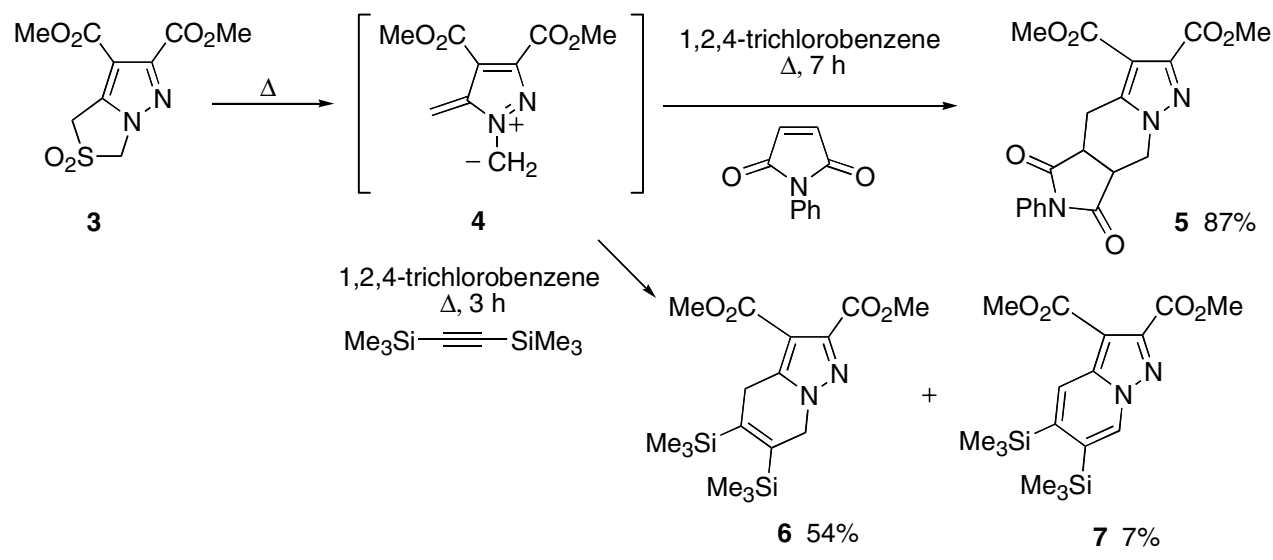

Scheme 1.

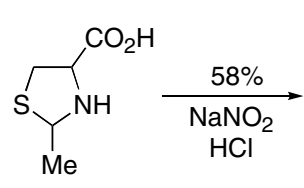

8

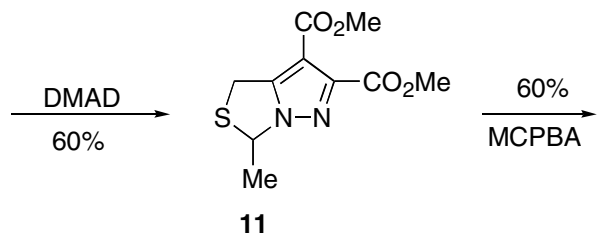

11

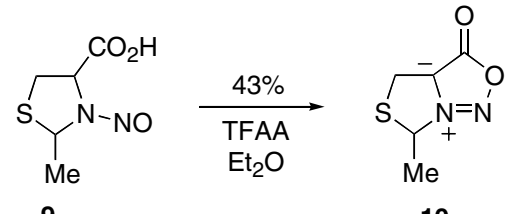

10<smiles>COC(=O)c1nn2c(c1C(=O)OC)CS(=O)(=O)C2C</smiles>

12 


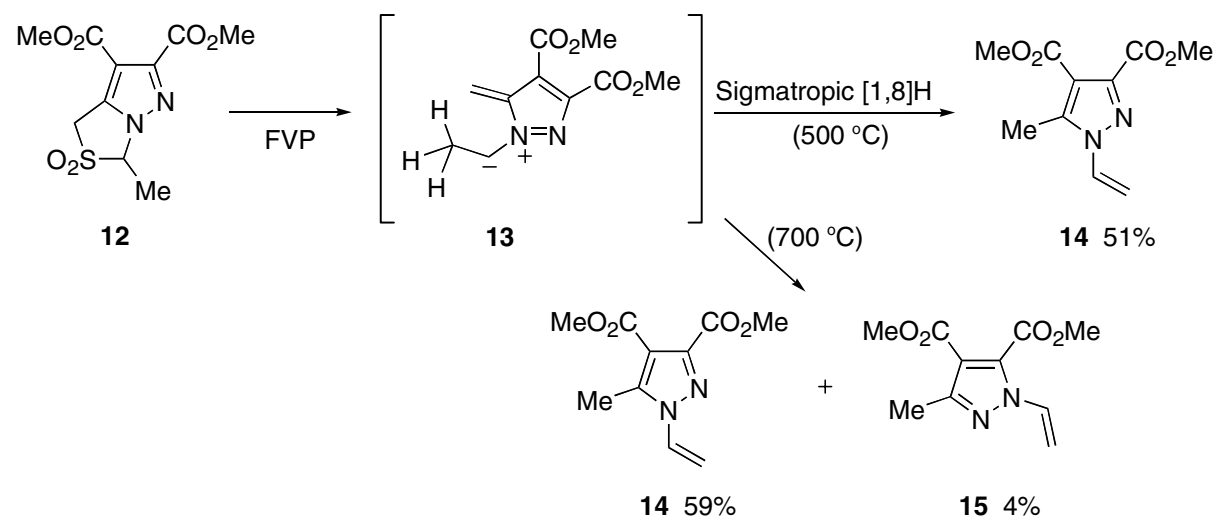

Scheme 3.

with 1-vinyl-1 $H$-pyrazole 15 . The FVP of 5-methyl-1vinyl- $1 H$-pyrazole 14 led only to sublimation of this compound and to the formation of a small percentage of 3-methyl-1-vinyl-1 $H$-pyrazole derivative $\mathbf{1 5}$ (Scheme 3).

The mechanism of conversion of pyrazolo[1,5-c][1,3]thiazole-2,2-dioxides into 1-vinyl- $1 H$-pyrazole involves the generation of diazafulvenium methide $\mathbf{1 3}$ which is trapped in an allowed, suprafacial $[1,8] \mathrm{H}$ sigmatropic shift. This reactivity, observed for the first time for the diazafulvenium methide derivatives, is similar to the one shown by azafulvenium methides $2 \mathbf{a}, \mathbf{f}-\mathbf{k}$ and $\mathbf{2 m}$. $^{4}$ However, 5-methyl-1-vinyl- $1 H$-pyrazole 14 proved to be more stable under FVP reaction conditions than the $N$-vinylpyrroles obtained previously from azafulvenium methides. In fact, 5-methyl-1-vinyl- $1 H$-pyrazole 14 was recovered almost unchanged on FVP whereas the $\mathrm{N}$-vinylpyrroles are converted into 5 -oxo- $5 \mathrm{H}$ pyrrolizines.

3-Methyl-pyrazolo[1,5-c][1,3]thiazole-2,2-dioxide 12 also undergoes $\mathrm{SO}_{2}$ extrusion in the solution to give 13, which can be intercepted in $8 \pi+2 \pi$ cycloadditions with $N$-phenylmaleimide and dimethyl acetylenedicarb- oxylate giving the corresponding adducts resulting from the addition across the 1,7-positions in high yields (Scheme 4). An attempt to react $\mathbf{1 3}$ with bis(trimethylsilyl)acetylene led only to the synthesis of 1-vinyl-1 $H$ pyrazole 14 in $16 \%$ yield.

In conclusion, in this letter, we describe new diazafulvenium methides' chemistry. These intermediates can be generated via thermal sulfur dioxide extrusion of pyrazolo[1,5-c][1,3]thiazole-2,2-dioxides.

The $\mathrm{SO}_{2}$ extrusion of pyrazolo[1,5-c][1,3]thiazole-2,2dioxides occurs more easily than from the analogous pyrrolo sulfones and can be carried out in refluxing 1,2,4-trichlorobenzene. The diazafulvenium methides, generated this way, can be intercepted in $8 \pi+2 \pi$ cycloadditions giving adducts resulting from the addition across the 1,7-position. This type of reactions is an interesting approach to the synthesis of pyrazolo[1,5-a]pyridine derivatives, a class of compounds with potential interest as antiherpetics. ${ }^{7}$ In the absence of dipolarophiles, the 1-methyl-diazafulvenium methide, generated under FVP reaction conditions, undergoes an intramolecular sigmatropic $[1,8] \mathrm{H}$ shift giving 1-vinyl- $1 \mathrm{H}$ pyrazoles.

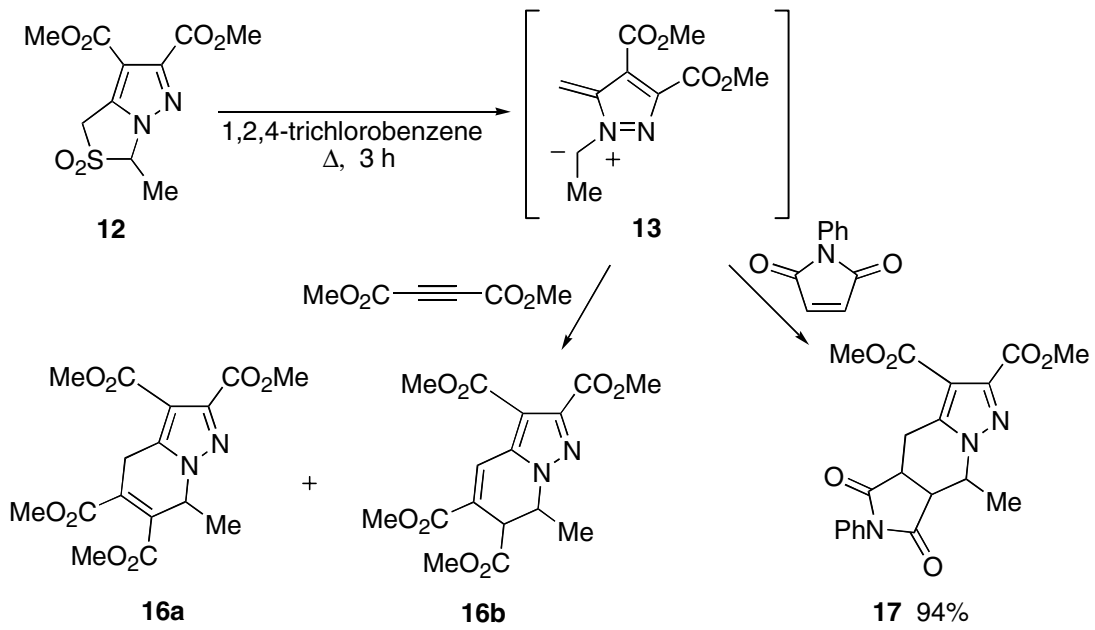




\section{Acknowledgements}

We thank Chymiotechnon and Fundação para a Ciência e a Tecnologia (POCI/QUI/55584/2004 and SFRH/BD/ 9123/2002), for financial support.

\section{References and notes}

1. (a) Sutcliffe, O. B.; Storr, R. C.; Gilchrist, T. L.; Rafferty, P.; Crew, A. P. A. Chem. Commun. 2000, 675-676; (b) Sutcliffe, O. B.; Storr, R. C.; Gilchrist, T. L.; Rafferty, P. J. Chem. Soc., Perkin Trans. 1 2001, 1795-1806.

2. Padwa, A.; Fryxell, G. E.; Gasdaska, J. R.; Venkatramanan, M. K.; Wong, G. S. K. J. Org. Chem. 1989, 54, 644652.

3. Sutcliffe, O. B.; Storr, R. C.; Gilchrist, T. L.; Rafferty, P. Tetrahedron 2000, 56, 10011-10021.

4. (a) Pinho e Melo, T. M. V. D.; Soares, M. I. L.; Rocha Gonsalves, A. M. d'A.; McNab, H. Tetrahedron Lett. 2004, 45, 3889-3893; (b) Pinho e Melo, T. M. V. D.; Soares, M. I. L.; Rocha Gonsalves, A. M. d'A.; Paixão, J. A.; Matos Beja, A.; Ramos Silva, M. J. Org. Chem. 2005, 70, 66296638.

5. Dimethyl 5,7-dioxo-6-phenyl-4a,5,6,7,7a,8-hexahydro-4Hpyrazolo[1,5-a]pyrrolo [3,4-d]pyridine-2,3-dicarboxylate $\mathbf{5}$. A suspension of dimethyl 5,5-dioxo-4H-pyrazolo[1,5-c][1,3]thiazole-2,3-dicarboxylate-2,2-dioxide $3(0.16 \mathrm{~g}, 0.58$ $\mathrm{mmol}$ ) and $N$-phenylmaleimide ( 2 equiv, $0.20 \mathrm{~g}, 1.16 \mathrm{mmol}$ ) in 1,2,4-trichlorobenzene $(1.8 \mathrm{~mL})$ was heated at reflux under dry nitrogen for $7 \mathrm{~h}$. After cooling to room temperature, the mixture was purified by flash chromatography [hexane] to remove 1,2,4-trichlorobenzene followed by elution with ethyl acetate-hexane (2:1), then ethyl acetate-hexane (4:1) to give 5 as a white solid (87\%). Mp $144.8-146.7^{\circ} \mathrm{C}$ (from diethyl ether). $v(\mathrm{KBr}) 1150,1221$,
1385, 1497 and $1715 \mathrm{~cm}^{-1} ; \delta_{\mathrm{H}}\left(\mathrm{CDCl}_{3}, 300 \mathrm{MHz}\right): 3.20$ $(1 \mathrm{H}, \mathrm{dd}, J=7.2$ and $16.4 \mathrm{~Hz}), 3.58-3.70(2 \mathrm{H}, \mathrm{m}), 3.85(3 \mathrm{H}$, s), $3.93(3 \mathrm{H}, \mathrm{s}), 3.93-4.00(1 \mathrm{H}, \mathrm{m}), 4.31(1 \mathrm{H}, \mathrm{dd}, J=5.7$ and $13.9 \mathrm{~Hz}), 4.90(1 \mathrm{H}, \mathrm{dd}, J=2.5$ and $13.9 \mathrm{~Hz}), 7.07-7.10$ $(2 \mathrm{H}, \mathrm{m}, \mathrm{Ar}-\mathrm{H}), 7.37-7.44(3 \mathrm{H}, \mathrm{m}, \mathrm{Ar}-\mathrm{H}) ; \delta_{\mathrm{C}}\left(\mathrm{CDCl}_{3}\right.$, $75.5 \mathrm{MHz}$ ): $22.5,37.1,40.4,46.1,51.9,52.6,112.0,126.1$, $129.0,129.2,131.0,141.5,143.3,162.0,174.9,176.0 ; \mathrm{m} / z$ (EI) $383\left(\mathrm{M}^{+}, 28 \%\right), 351$ (100), 204 (61), 176 (12), 147 (7), 119 (8) and 77 (7). Anal. Calcd for $\mathrm{C}_{19} \mathrm{H}_{17} \mathrm{~N}_{3} \mathrm{O}_{6}: \mathrm{C}, 59.53$; H, 4.47; N, 10.96. Found: C, 59.49; H, 4.64; N, 10.84.

6. Dimethyl 5-methyl-1-vinyl-1H-pyrazole-3,4-dicarboxylate 14. Pyrolysis of dimethyl 3-methyl- $1 H, 3 H$-pyrazolo[1,5-c][1,3]thiazole-6,7-dicarboxylate-2,2-dioxide $12(0.21 \mathrm{~g}, 0.73$ $\mathrm{mmol})$ at $500^{\circ} \mathrm{C} / 2 \times 10^{-2}$ mbar onto a surface cooled at $-196^{\circ} \mathrm{C}$ over a period of $1 \mathrm{~h}$ gave a colourless pyrolysate. [The rate of volatilisation of the starting material was controlled by the use of a Kugelrohr oven which heated the sample at $100-250{ }^{\circ} \mathrm{C}$.] After cooling to room temperature the pyrolysate was removed from the cold finger with dichloromethane and the solvent was removed in vacuo. The crude product was purified by flash chromatography [ethyl acetate-hexane (1:2), then ethyl acetate-hexane (1:1)] to give 14 as a white solid $(51 \%)$. Mp $46.3-48.0^{\circ} \mathrm{C}$ (from diethyl ether-hexane). $v$ (KBr) 1088, 1269, 1320, 1648, 1719 and $1740 \mathrm{~cm}^{-1} ; \delta_{\mathrm{H}}\left(\mathrm{CDCl}_{3}, 300 \mathrm{MHz}\right): 2.56(3 \mathrm{H}, \mathrm{s}), 3.85$ $(3 \mathrm{H}, \mathrm{s}), 3.95(3 \mathrm{H}, \mathrm{s}), 5.14(1 \mathrm{H}, \mathrm{dd}, J=0.9$ and $8.8 \mathrm{~Hz}), 5.95$ $(1 \mathrm{H}, \mathrm{dd}, J=0.9$ and $15.2 \mathrm{~Hz}), 6.99(1 \mathrm{H}, \mathrm{dd}, J=8.8$ and $15.2 \mathrm{~Hz}) ; \delta_{\mathrm{C}}\left(\mathrm{CDCl}_{3}, 75.5 \mathrm{MHz}\right): 10.3,51.7,52.5,106.4$, $112.6,128.2,142.9,144.4,162.8,163.0$; MS (EI) $\mathrm{m} / z 224$ $\left(\mathrm{M}^{+}, 28 \%\right), 193$ (100), 163 (27), 133 (12) and 68 (9). Anal. Calcd for $\mathrm{C}_{10} \mathrm{H}_{12} \mathrm{~N}_{2} \mathrm{O}_{4}$ : C, 53.57; H, 5.39; N, 12.49. Found: C, 53.75; H, 5.28; N, 12.39 .

7. Johns, B. A.; Gudmundsson, K. S.; Turner, E. M.; Allen, S. H.; Samano, V. A.; Ray, J. A.; Freeman, G. A.; Boyd, F. L., Jr.; Sexton, C. J.; Selleseth, D. W.; Creech, K. L.; Moniri, K. R. Biorg. Med. Chem. 2005, 13, 2397-2411. 